\title{
Culture, Motivational Attributes and Employees' Perception towards CSR Practices: Evidence From Pakistan
}

\author{
Sultana Jabeen \\ Karachi University Business School, University of Karachi, Pakistan \\ E-mail: Sultanajabeen22@gmail.com \\ Danish Ahmed Siddiqui \\ Karachi University Business School, University of Karachi, Pakistan \\ E-mail: daanish79@hotmail.com
}

Received: November 7, 2019 Accepted: December 18, 2019 Published: December 21, 2019

doi: 10.5296/hrr.v3i1.15785 URL: https://doi.org/10.5296/hrr.v3i1.15785

\begin{abstract}
The purpose of this paper is to analyze the employees-corporate social responsibility (CSR) relationship by studying the influence of two cultural values - collectivism and masculinity -on the formation of CSR perceptions. We adopted theoretical framework proposed by Hur and Kim (2017), in which Hofstede's cultural framework was proposed to explain the effect of the cultural values on employees' perceptions of CSR practices with the mediatory role of motivational attributions. To establish this framework empirically on Pakistan, a survey questionnaire was used to collect data from 190 employees' in Pakistan. Data analysis was performed using SEM and CFA. The results indicate that collectivistic (masculine) values were positively (negatively) related to perceptions of CSR. Furthermore, intrinsic attributions of CSR initiatives mediate the positive relationship between collectivism and CSR perceptions and the negative relationship between masculinity and CSR perceptions. These findings suggest that managers must seek to understand employees' cultural characteristics and the attributions of CSR motivations in order to engage them in driving CSR practices effectively and displaying a positive image of organization.
\end{abstract}

Keywords: Collectivism, Corporate social responsibility, CSR employees' perceptions, Masculinity, Pakistan, SEM, CFA 


\section{Introduction}

\section{1-Background of Study}

In recent days, corporate social responsibility is no more a competitive advantage but has turned into a firm's strategic necessity (Falkenberg \& Brunsæl, 2011). According to a recent global study of managers, two-thirds of respondents view investments in CSR as a competitive necessity, with another $68 \%$ upping their CSR commitments. Studies have consistently verified the benefits of doing CSR practices for organizational stakeholders, specifically, shareholders', management and consumers (Story \& Neves, 2014). If any organization decides not to engage in CSR, it may harm its brand and reputation which will cause a shortfall in long term profitability. On the other hand, if it is engaged in CSR activities by cutting budgets of its employees or mistreating employees, it will also not benefit a firm. So, it is crucial for companies to engage stakeholders in order to implement their CSR practices successfully, and employees are one primary and most important group of such stakeholders (Zhang, 2010). However, organization is usually unaware of how employees perceive and whether they admire such organizational exertions in CSR (Kuoppala, Lamminpa“a, Tomppo, Sc, \& Hinkka, 2011). Data from CCL's World Leadership Study also support this finding: employees' perceptions of their organizations' concern for community and environment is linked to their level of organizational commitment. Employees' perceptions of CSR make a unique and positive contribution to overall commitment. That is, the higher an employee rates their organization's corporate citizenship level, the more committed they are to the organization (Stawisk, Deal, \& Gentry, 2010).

Culture plays a vital role in setting perception regarding CSR. According to (Crane \& Matten, 2004), it has a significant effect on ethical beliefs and CSR evaluations. Ethical decision-making, ethical orientation and ethical values are highly influenced by culture (Hunt \& Vitell, 1986). Consequently, people from cultures or countries may believe that companies have varying societal responsibilities, leading them to have varying insights of CSR activities (Agudo-Valiente, Ayerbe, \& Figueras, 2015).

In this article, we will discuss the work of Hofstede (1979, 1980, 1983, and 1984); who provided a well-known framework in which he analyzed the mindset of managers, the corporate within the context of a set of cultural dimensions characteristic of different societies can be studied. To understand the effect of cultural values, we introduce employees' attributions of CSR as possible mediators linking cultural values to CSR perceptions.

\subsection{Problem Statement}

The most important task a corporate executive performs is to manage all stakeholders, including corporate shareholders. In these days, a new concept is attached in CSR i.e. protection of natural environment and local community development along with the betterment of employees and customers at the same time. Culture plays a vital role in driving a society's basic thoughts, values and behaviors' and it has an important role in setting the perception and value of CSR (Katz, Swanson, \& Nelson, 2001). It is the culture that has developed variety of values that are often reflected at individual level (Izraeli, 1998). So, it is important for the organizations to analyze cultural aspects with respect to building perceptions of employees of its CSR initiatives. The problem, usually observed in the 
organizations is that it is misunderstood in Pakistan that CSR is totally linked with enhancing consumers' attachment and loyalty with the brand and gaining financial outcomes. Well-being which was the basic factor of doing CSR is totally ignored. It is also a misconception that employees have nothing to do with it. According to (Campbell, 2007), in these days, organizations if avoid themselves getting engaged in CSR may endanger their brand and reputation. On the contrary, companies may also be criticized by their stakeholders if they initiate CSR activities by skimping on product quality or by mistreating employees. So in these days, it is equally important for the management to build employees' perception regarding its CSR programs. Organizations also faces problem in the context of culture. They have few knowledge about the aspects of culture so in this research paper it is guided how organizations can attach different cultural dimensions' to analyze employees' perception of CSR, for example, it is analyzed how two cultural dimensions i.e. Employees Collectivism and Employees Masculinity of Hofstede cultural framework impact on formation of employees perception regarding organization's CSR programs. Once the organization is able to understand the employees' perceptions of CSR thoroughly, they will be able to mold it according to the desired strategic objectives of CSR.

\subsection{Gap Analysis}

CSR has not only become commonplace among business corporations but a body of academic literature has also emerged around it. Beyond an initial debate over whether corporations ought to engage in CSR, much of the literature on CSR has focused on determining the specific meanings of CSR as well as the practical methods for implementing CSR in order to maximize financial wealth and improving consumer perception towards CSR. For example, (Story \& Neves, 2014), (Eilbirt \& Parket, 1973), (Hur \& Kim, 2007). But unfortunately little research has towards employees' aspect of CSR in Pakistan and other world. For example (Story \& Neves, 2014) discusses how corporate social responsibility impact the performance of employees. It is found that employee task performance and employees attribute both intrinsic and extrinsic motives for CSR have a significant relationship. When employees perceive that their organization invests in a CSR practice that is both intrinsic and extrinsic, they also tend to exert extra effort in their work. The limitation of this paper was it ignored the different cultural aspect which also influences employees' perception and ultimately impact on employees' performance. Another studies conducted in China by (Zhu, Hang, Liu, \& Kee-, 2012) to analyze how employees perceive organizational efforts in corporate social responsibility. Results of the research show that employee involvement is important for a company to successfully implement its CSR practices. Perception of corporate citizenship including CSR practices by companies influences affectively commitment by employees. Study is limited in revealing how to increase employee effort by jointly increasing perceived company effort and employee satisfaction need.

(Hofman \& Newman, 2013), examines the relationship between employees' perceptions of corporate social responsibility practices and their organizational commitment. Data was gathered from 280 employees of manufacturing firms in China. Analysis indicates that employee perceptions of corporate social responsibility practices towards internal stakeholders i.e. employees' were found to relate positively to their organizational 
commitment. In addition, the collectivism and masculinity orientations of employees were found to moderate this relationship. The results provide an insight into how corporate social responsibility practices may be utilized to motivate diverse groups of employees within China-based organizations. However this study is limited to the specific manufacturing industry in China.

(Hur \& Kim, 2007), in their studies specifically reveal the relationship of two influential cultural values i.e. collectivism and masculinity on the consumers' perception of CSR. They also used intrinsic and extrinsic attributes of CSR as a motivational attributes of CSR. Research reveals that collectivistic (masculine) values are positively (negatively) related to perceptions of CSR. Furthermore, intrinsic attributions of CSR initiatives mediate the positive relationship between collectivism and CSR perceptions and the negative relationship between masculinity and CSR perceptions. However this research paper focuses only on the external stakeholder i.e. consumer. Whereas the perception of employees is totally ignored. Various studies have been conducted in Pakistan on the subject of employees' perception of corporate social responsibility to analyze the impact on employee outcomes with the mediating role of organizational justice. For example (Sarfraz, Qun, Abdullah, \& Alvi, 2018) discussed how corporate social responsibility can serve as the best motivator to motivate employees and opting desired outcomes. However this study focuses on SMEs employees' issues with the perception of CSR.

This paper investigates how cultural values influence the building of employees' perception toward the CSR practices of their organizations. Individually held cultural value orientations play an important role in the nature of employees' perception of different CSR activities by the organization. Specifically, the extent to which the collectivism and masculinity orientation of employees impact on CSR practices on organizational will be examined given that Pakistani culture has been characterized as being high in collectivism and masculinity. The findings of this research should be of benefit to domestic and foreign organizations operating in Pakistan and all other countries with highly collectivist and masculine culture, enabling them to determine where it is best to focus their CSR activities to improve their perceptions of CSR so that organizations can maximize the commitment of their employees.

\subsection{Research Objectives}

In under developing countries like Pakistan, consumer is considered as King whereas employees who are the most crucial internal stakeholders are always given less importance and as a result their organizations less prioritize their perceptions. Aim of this research paper is to highlight the importance of the perception of primary stakeholders i.e. employees in designing CSR activities so that organizations consider this aspect and involve employees for initiating significant CSR practices for the community. This study contributes to the idea of CSR priority by understanding corporate social responsibility impact on employee's behaviors, and the influence of cultural values i.e. collectivism and masculinity on the perception of CSR. It has been discussed comprehensively how culture influences individual employees' perception towards CSR in this article. This research will help organizations to better understand the importance of having positive employees' perception towards their CSR programs so that CSR programs for the external stakeholders can be designed in a better way and with the support of internal stakeholders. 


\section{5 -Research Questions}

I-How collectivist values impact on employees' perception towards CSR?

II- How does masculine values negatively influence on employees perception towards CSR?

III- what is role of intrinsic attributes in building of employees perception towards CSR considering collectivists values?

IV- How does extrinsic attributes of CSR mediate negative relationship between employees perception of CSR and collectivists values?

V- How does intrinsic attributes of CSR form a negative relationship between masculine values and employees CSR perceptions?

VI- What kind of relationship do extrinsic attributes of CSR form in between employees perception of CSR and masculine values?

\section{6-Significance}

In developing countries like Pakistan, it is misunderstood usually that CSR is mainly done for consumers only in order to remind them brand name and getting their loyalty back in term of influencing their buying decision. Consumers prospective towards CSR practices is valued whereas employees' insights towards CSR is always neglected. Thus, the study will contribute practice and theoretical knowledge related to the significant importance of employees' perception towards CSR practices. It will be beneficial for all business sectors to learn the role of employees' perception in relation with the cultural values and motivational attributes in context of CSR practices, which will enable them to optimize their CSR strategy. Policy makers, top management and human resource personnel can utilize the recommendations provided in this paper for driving an effective CSR strategy. So that employees 'perception of CSR can be improved. As a result, they will be more committed with their work and organization.

The scope of this study is limited to industries of Pakistan and other countries where culture is highly masculine and collectivists. Employees in the industries of Pakistan usually have collectivist mindset so they have a different CSR practices perception. Management can utilize this paper in developing their thought about CSR practices.

\section{Literature Review}

\subsection{Culture and CSR}

In context of CSR, ethics in business has become a most interesting topic for scholars. Various scholars highlights the importance of ethical factors in their cultural frameworks (Vitell, Nwachukwu, \& Barnes, 1993). Thus, most of the time culture is studied in context of individual ethical decision making (Vitell, Paolillo, \& Thomas, 2003); and ethical behavior of organization ( Scholtens \& Dam, 2007).

Hofstede consistently worked on cultural frameworks (1979, 1980, 1983, 1984 and presented a well-known framework that highlights the five different cultural dimensions that regulate the perception, mindset and behavior of various stakeholders such as managers, staff and consumers as well (Williams \& Zinkin, 2008). Hofstede Culture dimensions suggest that business practitioners that are from collectivist society are more receptive to group and intra-organizational influence. So they are strictly bound in group norms they belong. 
However, in individualist society group interests are not much valued (Vitell, Nwachukwu, \& Barnes, 1993).

National and international studies have used Hofstede's cultural dimensions to examine the cultural differences within same country in building perceptions of CSR (Hur \& Kim, 2007)., Culture explains that employees from the same nation may often form different CSR perceptions due to various subcultures and individual differences (Maignan \& Ferrell, 2000).For example, it is noted that some people within the same culture tend to be more individualistic whereas others lean towards to be more collectivistic. That is why Hofstede's cultural values can be widely used to observe individual beliefs regarding CSR. But sufficient and consistent research results are always left behind to clarify the relationship between culture and CSR perceptions (Williams \& Zinkin, 2008).

\subsection{The Effect of Cultural Values on CSR Perceptions: Collectivism and Masculinity}

There are total five dimensions in the Hofstede's (1980) cultural structure i.e. individualism/collectivism, power distance, masculinity/femininity, and uncertainty avoidance. The two value dimensions that specifically predict perception of business ethics and social responsibility in context of individual variations are individualism/collectivism and masculinity/femininity (Blodgett, Chuan, Rose, \& Vitell, 2001).

\subsubsection{Individualism}

Individualism is defined as the degree to which an individual is keen to pursue his own goal, to be Independent, self-oriented, competitive ,individual loses tie in society and individual has his/her own perceptions (Hofstede G. , 1984). They have a mindset that personal goals and interests are more important even when working in a group (Vitell, Paolillo, \& Thomas, 2003). They believe in personal independence and freedom to achieve their own rights without any interference (Peobody, 1985). Individuals seek isolation from rest of people while collectivists come to know inter-relating with others (Triandis, 1989). Almost individualists are selfish to gain personal interests without caring about ethics and rights.

\subsubsection{Collectivism}

In contrast, cultures where collectivism is valued people are strictly tied in with each other, they cooperate with each other and harmonize the environment (Hofstede, 1984). In collectivist society people from birth onwards are united into groups and throughout their lives work to secure group interests (Scholtens \& Dam, 2007). They chiefly don't consider themselves as individual but a member of extended family of the organization (Hofstede G. , 1984). Almost they are motivated to group success rather than self-profit. In a nutshell, collectivistic are pro social to the environmental problems (Puohiniemi, 1995).

The individualism/collectivism distinctions affect the relationship among various factors. According to (Wood, Longenecker, McKinney, \& Moore, 1988) individualism and collectivism are two strongest morally affecting elements for individuals in the context of CSR. In his studies, observed that the organizations with individualist culture are found less ethical as compare to the collectivists' cultures. Based on different findings, it is highlighted that the workers in individualist culture consider themselves more important than other stakeholders whereas the collectivist workers are more likely to safeguard ethical interests of other stakeholders. Collectivists firmly stick on organizational ethics and code of conducts 
even at the personal interests. On the other hand, individualists workers does not comply with any code of conduct of organization limits their personal gain (Blodgett, Chuan, Rose, \& Vitell, 2001).

Thus with the help of characteristics of collectivism identified from previous findings, we first hypothesize:

\section{H1: Collectivistic values are positively related to CSR perceptions}

Masculinity, another element of Hofstede's cultural framework characterized with the individual attributes like heroism, preference for achievement, material success and assertion (Hofstede G. , 1985). Masculine individuals are attracted towards money and material objects. They can easily engage in unethical code of conducts for their personal benefits. In contrast, feminist individuals are not welfare oriented. They are humanist and less interested in recognition and achievements. Thus they are less likely to engage in unethical behaviors (Hofstede, 1984). With the help of above findings, we can conclude our second hypothesis:

\section{H2: Masculine values are negatively related to CSR perceptions.}

Different stakeholders in the organization form a distinct CSR practices perception. The reason behind this different attribution is the formation of casual explanations on the basis of information they get for events including CSR practices. For instance, (Fiske \& Taylor, 1991), highlighted that importance of CSR is dependent on the roles assigned to individuals. Therefore, managers are usually more aware of CSR activities as compare to non-managers. Since individuals set a motive behind CSR practices based on their personal motives.

\subsection{The Mediating Role of CSR Attributions; Intrinsic and Extrinsic Attributes of CSR}

CSR perception is also affected by two attributive motives factors. These two factors impact on employees' perceptions can be divided as intrinsic and extrinsic attributes. Intrinsic CSR practices are described as practices perceived as sincere. Organizations are engaged in CSR practices because they care (Vlachos, Panagopoulos, \& Rapp, 2013). Therefore, employees surely believe that organization cares for the cause, if an organization spends for a social cause or in charity. This aspect is all about morality of the firm in which stakeholders have a blind trust of the character of the organization. Corporations are engaged in extrinsic practices with the view of getting something back or in order to avoid some kind of punishment from the community (Vlachos, Panagopoulos, \& Rapp, 2013). It does not mean that organizational practices are not up to the mark rather stakeholders may perceive that organization is investing in CSR practices in order to get some strategic advantages. Thus, this can be described as the 'business case' for CSR.

Consequently, collectivist employees are more interested to see intrinsic motivations and sincerity of the organization as they are being concerned about the community welfare resulting with positive perception about CSR. On the other hand, if they see organization is getting engaged in CSR practices just for its own branding and long term benefit. Definitely they will doubt on corporate's social practices.

Summing up, we can say employees' attributions significantly mediate the positive relationship between collectivism and CSR practices. Employees recognize a firm as more socially responsible when they believe that the firm is intrinsically motivated to benefit the Community and its stakeholders, but not when they believe that the firm is extrinsically 


\section{Macrothink

motivated to benefit the firm. Thus, we hypothesize the following:

H3: Intrinsic attributions mediate the positive relationship between collectivistic values and CSR perceptions.

H4: Extrinsic attributions mediate the negative relationship between collectivistic values and CSR perceptions.

Employees with strong masculine culture who only think about their personal advancement, growth and success are less likely to believe that the corporation is socially responsible to serve community (Vitell, Nwachukwu, \& Barnes, 1993). Being less socially sensitive they have a thought that organization is need not to take ethical CSR initiatives. Masculine individuals believe that employees should invest its resources to improve sales and equity (Hur \& Kim, 2007).In sum, they are more likely to support and positively perceive CSR that is driven by extrinsic, firm-serving motivations, and are less likely to support or positively perceive CSR driven by intrinsic, public-serving motivations. Accordingly, we hypothesize thus:

H5: Intrinsic attributions mediate the negative relationship between masculine values and CSR perceptions.

H6: Extrinsic attributions mediate the positive relationship between masculine values and CSR perceptions.

3. Theoretical Framework

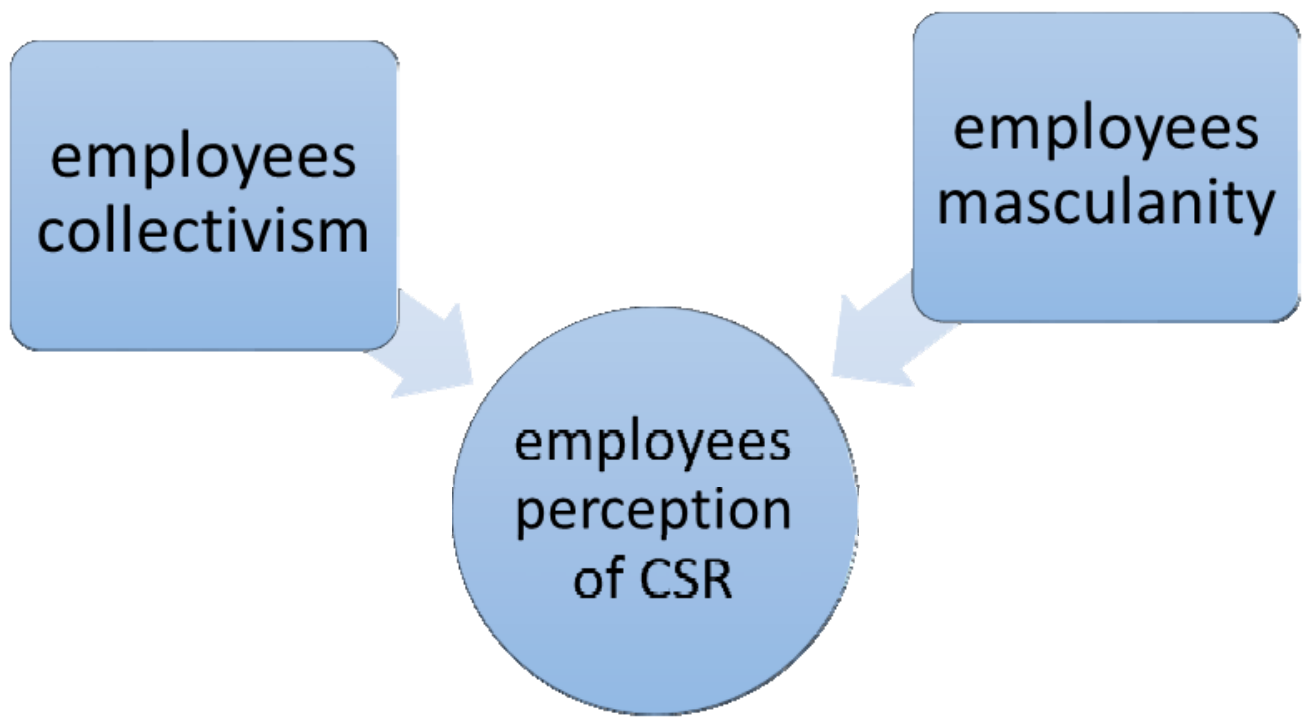




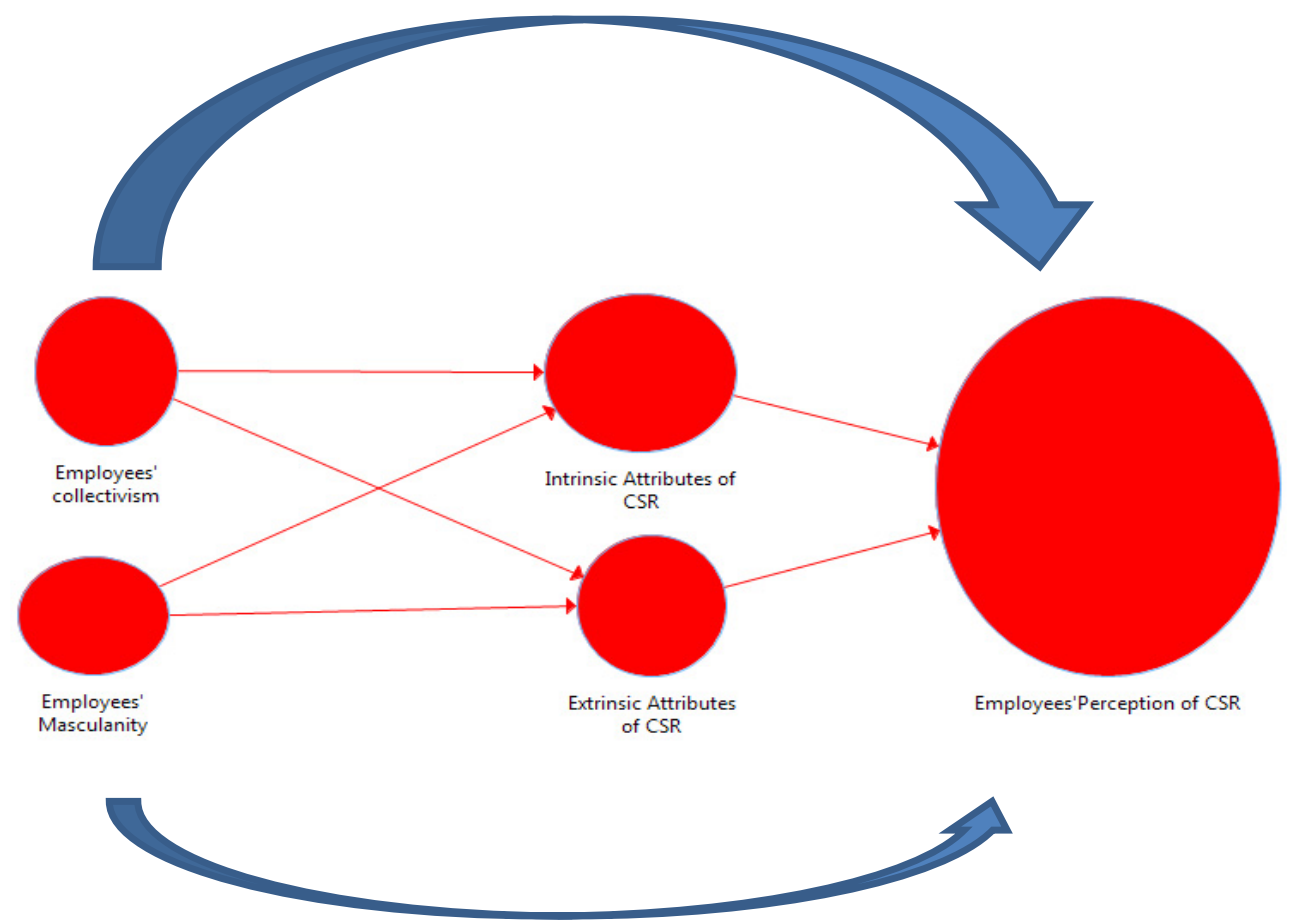

(Hur \& Kim, 2007), conducted a research and thoroughly discussed how Hofstede's cultural model can be used to analyze the perception of consumers towards organization's efforts for CSR. It is figured out that collectivism and masculinity, as two independent variables, affected consumers' perception towards CSR. It is evident that consumers from different cultures have different perceptions for CSR. Those who are from collectivist cultural values give much importance to organization's' efforts for the social wellbeing. On the other hand, consumers with masculine values pay little attention towards organization's CSR initiatives. Any organization if firstly analyze the cultural aspects of the society, may adopt and implement CSR activities successfully. Similarly, employees' reaction to CSR depend greatly on their perception about corporation motives and their attributions in terms of CSR outcomes.

When employees believe a company is sincerely motivated to undertake CSR, employees tend to react favorably and have a positive image of organization in their mindset. On the contrary, if its motivations are questionable, a company and its activities may be viewed cynically and negatively. Thus, perceived motivations play a meaningful role in CSR perceptions by mediating the effect of CSR awareness. Consequently, the literature indicates that employees' attributions regarding firms' underlying motives for pursuing CSR will determine employees' perceptions of CSR. To understand the effect of cultural values, we introduce employees' attributions of CSR as possible mediators linking cultural values to CSR perceptions. We develop and test a conceptual model proposing a direct relationship between cultural values and CSR perceptions, and an indirect relationship between them via CSR attributions.

\subsection{Research Hypothesis}

H1: Collectivistic values are positively related to CSR perceptions 
H2: Masculine values are negatively related to CSR perceptions.

H3: Intrinsic attributions mediate the positive relationship between collectivistic values and CSR perceptions.

H4: Extrinsic attributions mediate the negative relationship between collectivistic values and CSR perceptions.

H5: Intrinsic attributions mediate the negative relationship between masculine values and CSR perceptions.

H6: Extrinsic attributions mediate the positive relationship between masculine values and CSR perceptions.

\section{Research Methodology}

\subsection{Sampling Technique and Sample Size}

The sampling technique used for conducting this study is convenience sampling, i.e., data was collected with the personnel easily accessible and approachable. Convenience sampling is a non-probability sampling enables a researcher to gather data from the most easily and approachable contributors. The sample size taken for this paper consists of 190 individuals.

\subsection{Data Collection Method}

Data was collected using Primary data collection methodology using questionnaire survey, filled by employees of reputable companies that are engaged in CSR practices in Pakistan. Participants were fully informed about the research objectives and background.

\subsection{Instrumentation}

Formal and close ended questionnaire was used for this research survey which included statements based on 5-point Likert scale. These statements were developed by referring previous studies (Hur \& Kim, 2007) on the cultural effect on employees' perception. Each statement carried five options. Participants were allowed to select any one of the best options among five different choices.

\section{Data Analysis}

5.1 Descriptive Statistic

\begin{tabular}{llll}
\hline Variables & Groups & Frequency & Percentage \\
\hline Gender & Female & 36 & 19.1 \\
& Male & 154 & 80.9 \\
Age & Less than 25 & 27 & 14 \\
& $25-30$ & 69 & 36.3 \\
& $31-35$ & 46 & 24.2 \\
Tenure & $36-40$ & 24 & 12.7 \\
& Above 40 & 24 & 12.7 \\
& Less than a year & 23 & 12.1 \\
& $0-2 y e a r s$ & 40 & 21 \\
\hline
\end{tabular}




$\begin{array}{lll}\text { 3-5 years } & 59 & 31.2 \\ \text { 6-9 years } & 33 & 17.2 \\ \text { More than 10 years } & 35 & 18.5\end{array}$

Control variables used in this research are gender, age, work experience and sector of organization.

\subsubsection{Gender}

190 personnel participated in this survey, percentage of male respondents' remained $(80.9 \%)$ whereas, and female employees were (19.1\%).

\subsubsection{Age Group}

Most of the respondents were in the age group of 25-30 years i.e.(36.3\%).there were $24.2 \%$ employees belonged to age bracket of 31-35 years. 14\% of total individuals were less than 25 years of age. moreover, $12.7 \%$ were in both age groups i.e. $36-40$ and more than 40 years.

\subsubsection{Work Experience}

In this research article, the maximum number of respondents had the working experience of 3 to 5 years. $21 \%$ of total employees had 0 to 2 years of working experience. Furthermore, $18.5 \%$ of total were the most seniors' employees having more than 10 years of exposure. Individuals with 6-9 years of experience were $17.2 \%$ of total participants. The most junior category with less than a year of experience were $12.1 \%$ only.

\subsection{Collectivism Questionnaire}

\begin{tabular}{llll}
\hline QUESTIONS & $\begin{array}{l}\text { Sample } \\
\text { Mean (M) }\end{array}$ & S.E & $\begin{array}{l}\text { Standard } \\
\text { Deviation } \\
\text { (STDEV) }\end{array}$ \\
\hline $\begin{array}{l}\text { 1. In a collectivist culture, Individuals stick with the } \\
\text { group even though difficulties }\end{array}$ & 0.634 & 0.0040 & 0.056 \\
$\begin{array}{l}\text { 2. Group welfare is more important than individual } \\
\text { welfare. }\end{array}$ & 0.710 & 0.0032 & 0.045 \\
$\begin{array}{l}\text { 3. Group success is more important than individual } \\
\text { success }\end{array}$ & 0.771 & 0.0029 & 0.040 \\
$\begin{array}{l}\text { 4. Individuals should only pursue their goals after } \\
\text { considering the welfare of the group }\end{array}$ & 0.799 & 0.0018 & 0.026 \\
$\begin{array}{l}\text { 5. Group loyalty should be encouraged even if } \\
\text { individual goals suffer }\end{array}$ & 0.750 & 0.0026 & 0.037 \\
\hline
\end{tabular}

Employee collectivism is an independent variable consist of 5 items and the mean values of the items lie within the range of 0.662-0.876. The overall mean value is above average and it is more towards "Agree" at five point Likert scale. The standard deviation ranges between 
0.021-0.079 which indicates that the data is not dispersed and is close to the mean value of data.

\subsection{Masculinity Questionnaire}

\begin{tabular}{llll}
\hline QUESTIONS & MEAN & S.E & STD.D \\
\hline $\begin{array}{l}\text { It is more important for men to have a professional } \\
\text { career than it is for women }\end{array}$ & 0.875 & 0.0016 & 0.023 \\
$\begin{array}{l}\text { Men usually solve problems with logical analysis; } \\
\text { women usually solve problems with intuition. }\end{array}$ & 0.875 & 0.0015 & 0.021 \\
$\begin{array}{l}\text { Solving difficult problems usually requires an } \\
\text { active, forcible approach, which is typical of men }\end{array}$ & 0.819 & 0.0023 & 0.033 \\
\hline
\end{tabular}

Masculinity is an another independent variable having 3 items, the mean value of the items is in between 0.819-0.875.standard deviations of the values that lies between 0.021-0.033, shows data is not scattered.

\subsection{Intrinsic attributes of CSR Questionnaire}

\begin{tabular}{|c|c|c|c|}
\hline QUESTIONS & MEAN & S.E & STD.D \\
\hline $\begin{array}{l}\text { Your organization is genuinely concerned about } \\
\text { being socially responsible }\end{array}$ & 0.811 & 0.0025 & 0.035 \\
\hline $\begin{array}{l}\text { Your organization engages in socially responsible } \\
\text { initiatives because it feels morally obligated to help }\end{array}$ & 0.880 & 0.0013 & 0.019 \\
\hline $\begin{array}{l}\text { Your organization engages employees in socially } \\
\text { responsible initiatives in order to give back } \\
\text { something to the community including their own } \\
\text { staff. }\end{array}$ & 0.712 & 0.0044 & 0.061 \\
\hline
\end{tabular}

Intrinsic attributes of CSR is a mediating variable consisting 3 items, with the mean values placed between 0.712-0.811. The overall mean value is above average and it is more towards "Agree" at five point Likert scale. The standard deviation of 4 items ranges between 0.019-0.061 which specifies that the data is not dispersed and is close to the mean value of data. 


\subsection{Extrinsic Attributes of CSR Questionnaire}

\begin{tabular}{llll}
\hline QUESTIONS & MEAN & S.E & STD.D \\
\hline $\begin{array}{l}\text { Your organization engages in socially responsible } \\
\text { initiatives in order to get more customers. }\end{array}$ & 0.903 & 0.0010 & 0.015 \\
$\begin{array}{l}\text { Your organization engages in socially responsible } \\
\text { initiatives because it feels competitive pressures to } \\
\text { engage in such activities. }\end{array}$ & 0.893 & 0.0013 & 0.018 \\
$\begin{array}{l}\text { Your organization hopes to increase its profits by } \\
\text { engaging in socially responsible initiatives. }\end{array}$ & 0.911 & 0.00101 & 0.014 \\
\hline
\end{tabular}

Another mediating variable is extrinsic attributes of CSR giving 3 items. Calculations show the average value lying in the range of $0.893-0.911$ i.e. overall mean value is above the average. Standard deviation ranges between $0.014-0.018$ specifying that data is not dispersed.

\subsection{Employees'Perception of Organization's CSR Initiatives Questionnaire}

\begin{tabular}{lllll}
\hline QUESTIONS & MEAN & S.E & STD.D \\
\hline $\begin{array}{l}\text { Your organization is a socially responsible } \\
\text { company. }\end{array}$ & 0.662 & 0.0057 & 0.079 \\
$\begin{array}{l}\text { Your organization is concerned to improve the } \\
\begin{array}{l}\text { well-being of employees, customers and society. } \\
\text { Your organization supports good causes. }\end{array}\end{array}$ & 0.816 & 0.0025 & 0.035 \\
$\begin{array}{l}\text { Your organization behaves responsibly regarding } \\
\text { the environment. }\end{array}$ & 0.876 & 0.0015 & 0.021 \\
\hline
\end{tabular}

Employee perception of CSR is dependent variable with the average in between 0.662-0.876 having 4 items. The overall mean is above the average. Standard deviation lies between 0.021-0.079 indicating data is not scattered.

\subsection{Structural Equation Modeling}

To test the study hypothesis we have used the structural equation model (SEM) whereas the testing has been gone through Smart PLS software. Moreover, to evaluate the indirect and direct effects of all the constructs the testing was done. The use of (SEM) structural equation model has been observed to be a foremost procedure that has been used below different regression models and methods. It used to evaluate the structural relationship between exogenous and endogenous variables. It includes factor analysis and multivariate analysis. 


\section{Macrothink}

Human Resource Research

ISSN 1948-5441

2019, Vol. 3, No. 1

Moreover, the equation of regression targets at explaining each construct to assess the cause and effect relationship while all of the factors in the causal model could demonstrate their cause and effect at exact time. Likewise, the idea of using this model ensures to apply technique of bootstrapping which has been viewed as reasonable for both small and large sample size and does not require any kind of indirect effect. In order to check the all direct and indirect effects, a technique has been implemented which is known as bootstrapping.

\subsubsection{Measurement of Outer Model}

The goal of measure of fit in the measurement model is to study about the reliability and validity of the instrument and to check its reliability and validity we perform test of convergent validity and discriminant validity in software naming Smart PLS.

\subsubsection{Composite Reliability}

Reliability implies stability of questionnaire outcomes. For the similar target population, at whatever point the questioner reutilize the questionnaire it will give similar outcome. It demonstrates inside consistency \& repeatability of the survey is high. The primary measure for unwavering quality is to maintain a strategic distance from unfairness in research. In this manner, it tends to be improved by testing the pursuit procedure and investigation, as is done utilizing diverse research and examination techniques or different researchers. This also incorporates the dependability and legitimacy of the exploration.

Reliability of the measurement instruments was evaluated using composite reliability. All the values were above the normally used threshold value i.e. 0.70 . This is the accepted reliability value range. Estimation of reliability can be done by degree of constancy that lies amongst various variables (Hair , 2010). Below is the table of composite reliability.

\begin{tabular}{ll}
\hline VARIABLES & Composite Reliability \\
\hline Collectivism & 0.855 \\
Masculinity & 0.893 \\
Intrinsic & 0.846 \\
Extrinsic & 0.929 \\
Perception & 0.880 \\
\hline
\end{tabular}

\subsection{Factor Loadings Significant}

Below is the mentioned table of (CFA) confirmatory factor analysis with the loadings. Construct with the loading of .5 are consider as strong loading variables whereas the constructs with the loading of below .5 are considered as less are better to be removed from the table. 


\begin{tabular}{|c|c|c|c|c|}
\hline Variables & Constructs & Item loading & T-value & P-Value \\
\hline \multirow[t]{5}{*}{ Employees Collectivism } & $\mathrm{C} 1$ & 0.639 & 11.514 & 0.000 \\
\hline & $\mathrm{C} 2$ & 0.712 & 15.790 & 0.000 \\
\hline & $\mathrm{C} 3$ & 0.774 & 19.261 & 0.000 \\
\hline & $\mathrm{C} 4$ & 0.798 & 30.567 & 0.000 \\
\hline & C5 & 0.750 & 20.313 & 0.000 \\
\hline \multirow[t]{3}{*}{ Masculinity } & M1 & 0.875 & 38.700 & 0.000 \\
\hline & M2 & 0.874 & 41.406 & 0.000 \\
\hline & M3 & 0.822 & 24.852 & 0.000 \\
\hline \multirow[t]{3}{*}{ Intrinsic attributes of CSR } & I1 & 0.808 & 22.845 & 0.000 \\
\hline & $\mathrm{I} 2$ & 0.878 & 46.638 & 0.000 \\
\hline & $\mathrm{I} 3$ & 0.721 & 11.850 & 0.000 \\
\hline \multirow[t]{3}{*}{ Extrinsic attributes of CSR } & E1 & 0.902 & 58.982 & 0.000 \\
\hline & E2 & 0.893 & 48.794 & 0.000 \\
\hline & E3 & 0.912 & 63.477 & 0.000 \\
\hline \multirow{4}{*}{$\begin{array}{l}\text { Employees' perception towards } \\
\text { CSR }\end{array}$} & $\mathrm{P} 1$ & 0.668 & 8.440 & 0.000 \\
\hline & $\mathrm{P} 2$ & 0.819 & 23.586 & 0.000 \\
\hline & P3 & 0.842 & 30.851 & 0.000 \\
\hline & P4 & 0.876 & 42.656 & 0.000 \\
\hline
\end{tabular}

The table mentioned above is the Confirmatory Factor Analysis table with the loadings. The value of the variable loading if above 0.5 , consider as strong loading variable whereas if it is less than 0.5 , it is considered as weak. It is suggested, to ensure consistency of path analysis model, eliminate variables having loadings less than 0.5 .

In the table the loading values of all the constructs related to Employees Collectivism, Employees Masculinity, Intrinsic attributes of CSR ,Extrinsic attributes of CSR and Employees perception towards CSR are more than 0.7 except C1 (0.639) and P1 (0.668) which are also more than 0.5 . Resultantly, it supports strong loading values. The $\mathrm{T}$ values of all the constructs are more than 1.96 and $\mathrm{P}$ values are less than 0.05 (more than 99 percent confidence).

\subsection{Convergent Validity}

Convergent validity is the level of agreement in at least two measures of a similar construct if; the variance extracted value is greater than 0.5 then convergent validity is established and the result is drawn that the loadings are good but less than 0.5 are termed as less effective for the study. 
Following table displays the result.

\begin{tabular}{lllll}
\hline \multicolumn{4}{l}{ VARIABLES Cronbach's Alpha rho_A Composite Reliability Average Variance Extracted (AVE) } \\
\hline Collectivism & 0.794 & 0.811 & 0.855 & 0.543 \\
Masculinity & 0.820 & 0.826 & 0.893 & 0.735 \\
Intrinsic & 0.724 & 0.730 & 0.846 & 0.648 \\
Extrinsic & 0.886 & 0.886 & 0.929 & 0.815 \\
Perception & 0.817 & 0.844 & 0.880 & 0.649 \\
\hline
\end{tabular}

\subsubsection{Cronbach's Alpha}

To measure the reliability and consistency of the instrument Cronbach's alpha was used in this study. The instrument is said to be reliable, valid and consistent, if the value of Cronbach's alpha is greater than 0.7 and the ideal value of Cronbach's alpha lie within range of 0.7-1.collectivism is an Independent variable consist of 5 items and the Cronbach's alpha value is $(0.794)$ which indicates the reliability and internal consistency of items. The value of Cronbach's alpha for the masculinity with three items is (0.808). For the first mediating variable intrinsic attributes of CSR is 0.724 . The second mediating variable i.e. extrinsic attributes of CSR is 0.886 , both the variables having values greater than 0.7 . Lastly, employees' perception towards CSR, an independent variable, having Cronbach's alpha value (0.817) is more than 0.7. Hence, the independent, mediating and dependent all the variables show consistency, validity and reliability.

\subsubsection{Spearman Rank Correlation}

The association and strength among variables is specified by the Spearman rank correlation and the column subsequent to Cronbach's alpha represents it. The correlation values for different variables are, Employees Collectivism (0.811), Employee Masculinity (0.826), Intrinsic attributes of CSR (0.730), Extrinsic attributes of CSR (0.886) and Employee perception towards CSR (0.844) shows that the association among the variables is strong.

\subsubsection{Composite Reliability}

Composite reliability evaluates the internal consistency of scale items just like Cronbach's alpha. The values of composite reliability for different variables are $0.855,0.893,0.846$, 0.929 and 0.880 which indicates the validity and consistency of the items.

\subsubsection{Average Variance Extracted (AVE)}

The average variance for variables are $0.543,0.735,0.648,0.815$ and 0.649 . Since, the values are greater than 0.5 it indicates the loadings under these variables are good enough to support convergent validity.

\subsection{Discriminant Validity}

Discriminate validity results are satisfactory when the constructs are having an AVE loading more than 0.5 which means that minimum $50 \%$ of variance was took by the construct. Discriminate validity is established if the elements which are in diagonal are significantly 
higher than those values in off-diagonal in the parallel rows and columns. Discriminant Validity tests are being conducted in order to see whether non-related ideas or measurements are in fact unrelated or not. An effective assessment of discriminant legitimacy demonstrates that a trial of an idea isn't exceptionally associated with different tests intended to quantify hypothetically various ideas. The table for Discriminant Validity is given below:

\begin{tabular}{llllll}
\hline Variables & Collectivism & Extrinsic & Intrinsic & Masculinity & Perception \\
\hline Collectivism & 0.737 & & & & \\
Extrinsic & 0.747 & 0.903 & & & \\
Intrinsic & 0.500 & 0.615 & 0.805 & & \\
Masculinity & 0.494 & 0.508 & 0.585 & 0.857 & \\
Perception & 0.518 & 0.408 & 0.745 & 0.348 & 0.805 \\
\hline
\end{tabular}

The results of discriminate validity are acceptable when the AVE loading of the constructs are more than 0.5 which indicates that minimum $50 \%$ of variance was took by the construct (Chin, 1998) The validity is determined when the values in diagonal is higher than those which are in parallel row and column. All the values in the table is more than 0.5 except the values of employees masculinity and collectivism, employees perception of CSR and extrinsic attributes of CSR ad employees perception of CSR and employees masculinity which indicates that these elements does not have significant relationship in real. Other than that the above results shows that discriminate validity results are satisfactory

\subsection{Model Fit Measures}

The fitness of the model in SEM-PLS is defined by various measures such as standardized root-mean-square residual (SRMR), and the exact model fits like d_ULS and d_G, Normed Fit Index (NFI), and $\chi^{2}$ (Chi-square). The model fit measures consisting the measured value of both saturated model as well as the estimated model is reported in above Table. The saturated model assesses the correlation between all constructs. The estimated model, on the other hand, takes model structure into account and is based on total effect scheme.

Fit Summary

\begin{tabular}{lll} 
& Saturated Model & Estimated Model \\
\hline SRMR & 0.120 & 0.130 \\
d_ULS & 2.467 & 2.899 \\
d_G & 1.581 & 1.606 \\
Chi-Square & 1315.157 & 1405.735 \\
NFI & 0.533 & 0.501 \\
\hline
\end{tabular}




\section{Macrothink}

\section{Hypothesis Testing}

In PLS-SEM, bootstrapping is one of the key stride, which gives the data of constancy of factor guesstimate .Sub-tests are drawn everywhere from the first example including substitution, in this process (Hair, Matthews, Matthews, \& Sarstedt, 2017). Bootstrapping provides the information of stability of coefficient estimate. In this process, a large number of sub-samples are drawn from the original sample with replacement .After running the bootstrap routine, SmartPLS shows the t-values for structural model estimates derived from the bootstrapping procedure. The results of path coefficients for all the hypothesis are shown in the following table. The $\mathrm{t}$-value greater than $1.96(\mathrm{p}<.005)$ shows that the relationship is significant at 95\% confidence level $(\alpha=0.05)$. Paths showing whether the relationship between measured and latent variables are significant or not. The path diagram is shown below:

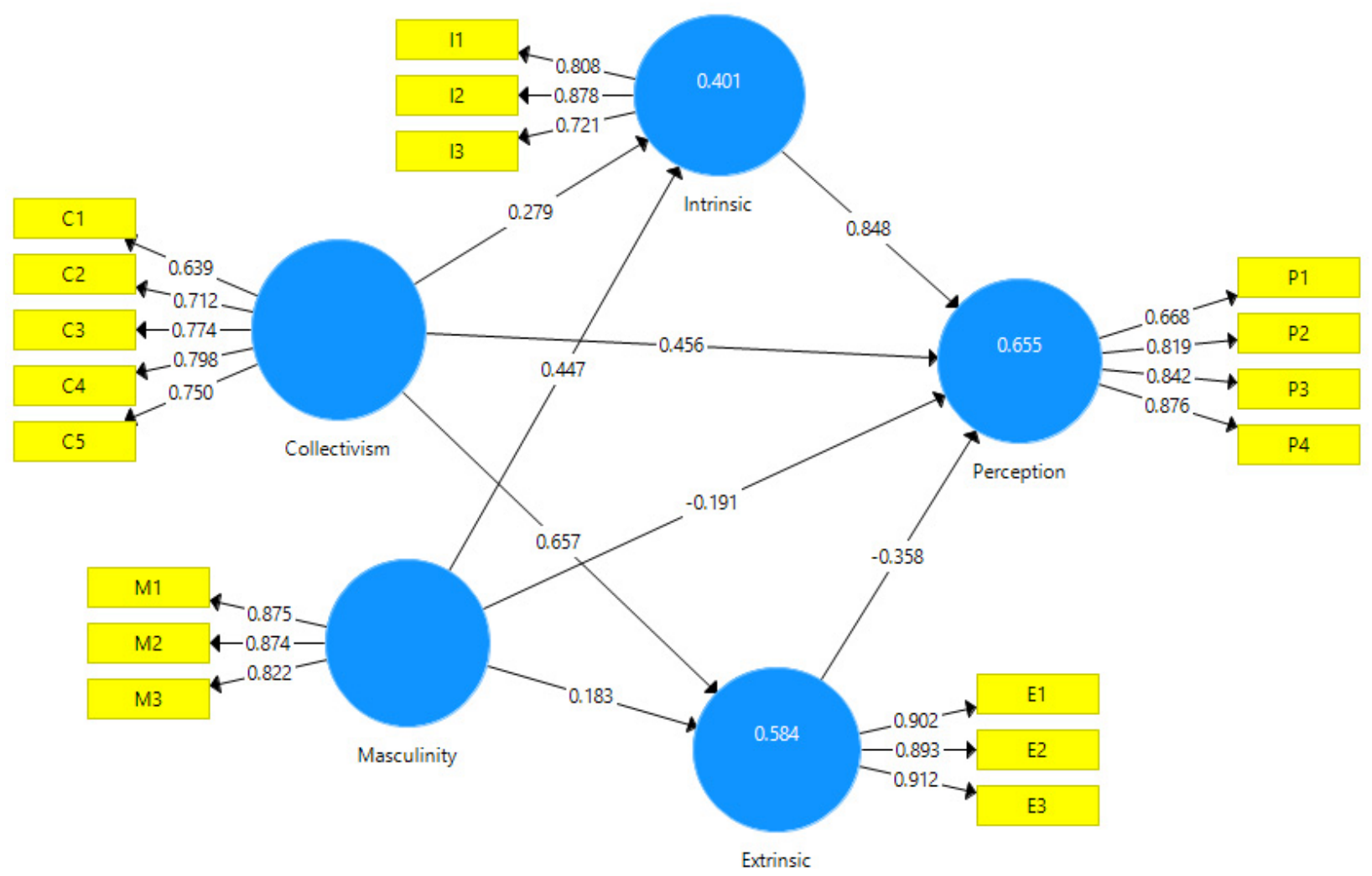

6.1 Results of Structural Model Path Coefficients

\begin{tabular}{lllll}
\hline Hypothesis & Path Coefficient & t-value & p-value & Conclusion \\
\hline $\begin{array}{l}\text { H1-Employees Collectivism } \\
\text { and CSR perception }\end{array}$ & 0.456 & 6.132 & $\mathbf{0 . 0 0 0}$ & Supported \\
$\begin{array}{l}\text { H2- Employees Masculinity } \\
\text { and CSR perception }\end{array}$ & -0.191 & 3.169 & $\mathbf{0 . 0 0 2}$ & Supported \\
\hline
\end{tabular}




\section{Macrothink}

The path coefficient of employees CSR perception due to employees collectivism is 0.456 and employees CSR perception due to employees masculinity is -0.191 showing strong relationship between dependent and independent variables. Likewise, t-values which are greater than 1.96, are also showing significance. The $p$ values are 0.000 less than 0.05 so, on the basis of $\mathrm{P}$ value the alternative hypothesis have been supported. The path coefficient of employees' collectivism to employees' perception of CSR is 0.456 representing a meaningful relationship between these two variables. It further explains that variation caused in the dependent variable i.e. $45 \%$ in employees' perception of CSR is significant owing to the $\mathrm{t}$-values which are greater than 1.96. The $\mathrm{p}$ values are 0.000 which is less than 0.05 and on the basis of $\mathrm{P}$ value the alternative hypothesis have been supported. Hence, It is acknowledged that Employees collectivism have a positive influence on employees perception of CSR . The path coefficient of employee masculinity to employees perception of CSR -0.191 indicates a meaningful negative relationship and explains that variation caused in the dependent variable i.e. 19.1\% in employees perception of CSR because of employees masculinity) is significant considering the $t$-value which is greater than 1.96 . The $p$ values are 0.002 which is less than 0.05 . Consequently, on the basis of $P$ value the alternative hypothesis have been supported. So, It is accepted that employees' masculinity have a negative influence on employees' perception of CSR.

\subsection{Mediating Role of Intrinsic and Extrinsic attributes of CSR}

\begin{tabular}{llll}
\hline Hypothesis & t-value & p-value & Conclusion \\
\hline $\begin{array}{l}\text { Intrinsic attributes of CSR- Collectivism } \\
\text { and Employees CSR Perception }\end{array}$ & & \\
$\begin{array}{l}\text { Extrinsic attributes of CSR-Collectivism } 15.169 \\
\text { and Employees CSR perception }\end{array}$ & 0.000 & Supported \\
$\begin{array}{l}\text { Intrinsic attributes of CSR -Employees } \\
\text { Masculinity and Employees CSR } 6.660\end{array}$ & 0.000 & Supported \\
$\begin{array}{l}\text { Perception Supported } \\
\text { Extrinsic attributes of CSR -Employees }\end{array}$ & & \\
$\begin{array}{l}\text { Masculinity and Employees CSR } 3.324 \\
\text { Perception } 0.000\end{array}$ & \\
\hline
\end{tabular}

The mediating role of Intrinsic and Extrinsic attributes of CSR in the relationship with Employees Collectivism and Masculinity for the Employees perception of CSR is assessed by the indirect effects of the bootstrapping test. The $\mathrm{T}$ values indicate a significant relationship among the variables as the $t$ values are 4.194, 15.169, 6.660 and 3.324 all are greater than 1.96. The $p$ values are 0.000 which is less than 0.05 and on the basis of $P$ value the alternative hypothesis have been supported. Similarly, it is proved that intrinsic attributes of CSR has a positive mediating relationship between Employees Collectivism and Employees perception 
of CSR, Extrinsic attributes of CSR has a negative mediating relationship between Employees Collectivism and Employees perception of CSR. Likewise, intrinsic attributes of CSR has a negative mediating relationship between Employees Masculinity and Employees CSR Perception. Likewise, extrinsic attributes of CSR has a positive mediating relation with Employees Masculinity and Employees CSR perception.

\section{Discussion}

The growing trend in business world is the expansion of CSR practices for sustainable growth. The concept of CSR is now no more limited to the consumers perspective but it has equally important for employees as well because employees are the most crucial stakeholder. It is mainly important to analyze their perception to engage them in taking decision related to different CSR strategies for all the stakeholders. Prior studies focused only one aspect i.e. how CSR initiatives improve business performance and how consumers perceive about CSR activities ( Maignan, 2001) .So, we strived to fill the research gap by extending it from consumers to employees and examining the psychological attributes driving the formation process of employees CSR perception.

Firstly, collectivism and masculinity (two cultural values) - for influences on employees' CSR perceptions investigated. Findings showed that collectivist employees have more positive CSR perceptions, on the contrary masculine employees have more negative CSR perceptions. Further, the literature is extended investigating the relevance of culture to CSR activities, it is clearly showed that employees' cultural values cause them to have different perceptions about the ethical and social responsibilities of corporations. Additionally, we improve the understanding of how culture affects the perceived importance of CSR activities. Previous studies have provided mixed evidences for the association between individualism and CSR evaluations (Christie, Kwon, Stoeberl, \& Baumhart, 2003); (Scholtens \& Dam, 2007); (Williams \& Zinkin, 2008). Here, we hypothesize and find that collectivistic employees have innate values regarding community solidarity and thus have positive perceptions of companies that are practicing CSR. Consequently, collectivist employees are conscious for CSR initiatives. They prefer community benefit on their personal goals. These employees present new ideas for the betterment of internal as well as external stakeholders such as better working conditions, employee pay benefits, quality goods and services etc. In contrast, masculine employees may have indifferent or negative attitudes about CSR because they are focused on competition and economic achievement rather than cooperation and solidarity. Therefore, they have less support for CSR, believing that monetary goals are being sacrificed for the benefits of external stakeholders.

Second, we examine the mediatory role of attributions in shaping the relationship between cultural values and CSR perceptions. For this we added two motivational attributes employees make to characterize their organization's CSR motives: intrinsic CSR practices and extrinsic CSR practices. Employees can discriminate between practices they believe to be morally consistent with their organization's intent to do well and practices they believe to be strategic for their organization. Employees are better exposed to the organization's history, culture, and values, and are better informed in making judgments about the organization. This is important because external stakeholders may care less about what firms are doing than why they are doing it in the formation of CSR perceptions (Gilbert \& Malone, 1995). 
Our research results suggest that intrinsic (i.e. altruistic) attributions fully not only mediate the positive relationship between collectivism and employees CSR perceptions but it also mediates the negative relationship between CSR perceptions and masculinity.

These findings confirm that intrinsic attributions can play a role as a sub-process regulating the effect of cultural values on employees' perceptions of CSR. For example, collectivistic employees tend to perceive positively a firm's social involvement, and this relationship can manifest via intrinsic motivations in corporate CSR actions. Whereas, masculine employees, being interested in material success, personal achievements and recognitions tend to perceive negatively a firm's CSR engagement through their negative attitudes toward intrinsic motivations underlying CSR. Intrinsic or socially focused motivations can be interpreted to be incongruent with their performance-oriented characteristics. In sum, employees with certain values tend to evaluate a firm's social responsibility according to their particular interpretation of the corporate motives underlying CSR actions.

Finally, as per hypothesis, our research results demonstrated that extrinsic attributes, another mediating variable, showed a positive relationship on the perceptions of employees with masculine mindset whereas collectivist employees had a negative attitude towards extrinsic CSR efforts.

\section{Conclusion}

The study was conducted to analyze the relationship of cultural values with the employees' perception of CSR. The results indicate that collectivistic (masculine) values are positively (negatively) related to perceptions of CSR. Furthermore, intrinsic attributions of CSR initiatives mediate the positive relationship between collectivism and CSR perceptions and the negative relationship between masculinity and CSR perceptions.

In order to develop an effective CSR strategy there is no such thing as best practices, but effective strategic CSR initiatives are those derived from careful analysis of the organization (e.g. its culture, competencies, and strategic vision) and these should be part of the strategy of the organization.

First, CSR practices need to be consistent with the moral values of the firm (i.e. intrinsic). Only practices that match the firm's values while retaining the focus on creating and adding value for business (bottom-line) improve employee perception about CSR. Aligning the core values, core business objectives, and core competencies and employees positive social perception of the organization is necessary in order to maximize both economic and social values over the long term (Bruch \& Walter, 2005) (Werther \& Chandler, 2011).

Our findings have practical implications for the management of successful CSR strategies. As per findings, employees' CSR perceptions are highly affected by cultural values. This research suggests the utility of understanding the relationships between the two cultural values and employees CSR perceptions. Where employees are strongly collectivistic, they have positive perception of company's image. They will be always ready to compromise their own goals for other members and external stakeholders. They are likely to harmonize with CSR programs that appear to care for the wellbeing of others and thus generate strong perceptions of CSR. However, if the employees are strongly masculine, managers should carefully consider what sort of CSR programs can improve their CSR perception as 
masculine employees care least about society. They will never compromise on their personal goals. If organization adopts any CSR initiatives program affecting masculine employees' personal objectives, they will build a negative image about the organization.

Secondly it is showed in the results, how motivational attributions mediate the cultural values-CSR perceptions link. According to research outcomes, for collectivist workforce, it is suggested that managers should carefully plans to design CSR activities to convey impressions that the company is sincere in its CSR efforts to benefit the public or the community. Although collectivistic employees will generally favor CSR, their positive perceptions can be mitigated if they fail to attribute intrinsic motives behind CSR actions. CSR practices need to be consistent with the moral values of the firm (i.e. intrinsic). In contrast, masculine employees who are more individualistic tend to be less discerning about a firm's CSR practices since they are less supportive of the intrinsic motives underlying CSR. Hence, when changing the perception of masculine employees, managers need to carefully plan and administer CSR programs to assure them that their individual performance or economic benefits will not be sacrificed by CSR investment.

\section{Future Research}

The limitations of this study are as following:

1) Time constraint limited researcher to adopt only quantitative method in order to gather the data. Future studies can be conducted by adding qualitative data.

2) The sample size comprised of 190 employees and does not represent the entire population of Pakistan. Convenience sampling technique is used which does not cover every sector of Pakistan.

3) This study did not cover specific CSR dimensions, despite the possible influence of different CSR dimensions, providing another area for future research.

4) We analyzed the influences of only two cultural values (i.e., collectivism and masculinity) on CSR perceptions.in order to provide more robust evidence on the culture-CSR link. Future research should consider including all of Hofstede's cultural dimensions.

5) Motivational attributions of CSR i.e. (intrinsic and extrinsic attributes) were observed as mediating variables. Future studies might incorporate values-driven, strategic, egoist, and stakeholder-driven CSR attributions.

6) Subsequent research should verify the current results in cross-cultural settings through conducting research in different countries.

\section{References}

Campbell, J. L. (2007, July). Why Would Corporations Behave in Socially Responsible Ways? An Institutional Theory of Corporate Social Responsibility. The Academy of Management Review, 32(3), 946-967. https://doi.org/10.5465/amr.2007.25275684

Hofstede, G. (2011). Dimensionalizing Cultures: The Hofstede Model in Context. Online Readings in Psychology and Culture. https://doi.org/10.9707/2307-0919.1014

Maignan, I. (2001, March). Consumers' Perceptions of Corporate Social Responsibilities: A Cross-Cultural Comparison. Journal of Business Ethics, 30(1), 57-72. https://doi.org/10.1023/ A:1006433928640 
Scholtens, B., \& Dam, L. (2007). Cultural values and international differences in business ethics. Journal of Business Ethics, 75(3), 273-284.

Zhang, J. (2010). Employee Orientation and Performance: An Exploration of the Mediating Role of Customer Orientation. Journal of Business Ethics, 91(1), 111-121. https://doi.org/10.1007/s10551-010-0570-6

Agudo-Valiente, J. M., Ayerbe, C. G., \& Figueras, M. S. (2015). Corporate Social Performance and Stakeholder Dialogue Management. Corporate Social Responsibility and Environmental Management, 22(I), 13-31. https://doi.org/10.1002/csr.1324

Blodgett, J. G., Chuan, L. L., Rose, G. M., \& Vitell, G. J. (2001). Ethical sensitivity to stakeholder interests: A cross-cultural comparison. Journal of the Academy of Marketing Science, 29(2), 190-202. https://doi.org/10.1177/03079459994551

Bruch, H., \& Walter, F. (2005). The Keys to Rethinking Corporate Philanthropy. MIT Sloan Management, 47, 49-55.

Chen, J. (n.d.). SUSTAINABLE INVESTING SOCIALLY RESPONSIBLE INVESTING (SRI). Retrieved from Investopedia: https://www.investopedia.com/terms/c/corp-social-responsibility.asp

Chin, W. W. (1998). The partial least squares approach for structural equation modeling. In G. A. Marcoulides, Modern Methods for Business Research (pp. 295-336).

Christie, P. M., Kwon, I.-W. G., Stoeberl, P. A., \& Baumhart, R. (2003, Sep). A Cross-Cultural Comparison of Ethical Attitudes of Business Managers: India, Korea and United States. Journal of Business Ethics, 46(3), 263-287. https://doi.org/10.1023/A:1025 501426590

Crane, A., \& Matten, D. (2004). Questioning the Domain of the Business Ethics Curriculum. Journal of Business Ethics, 54(4), 357-369. https://doi.org/10.1007/s10551-004-1825-x

E, J. E., \& E., D. K. (1965). From acts to dispositions: the attribution process in person. Advances in experimental social psychology. (L. Berkowitz, ed.), II, 219-266. https://doi.org/10.1016/S0065-2601(08)60107-0

Eilbirt, H., \& Parket, R. (1973, August ). The practice of Business: The current status of corporate social responsibility. Business Horizons, 16(4), 5-14. https://doi.org/10.1016/ 0007-6813(73)90043-8

Falkenberg, J., \& Brunsæl, P. (2011). Corporate Social Responsibility: A Strategic Advantage or a Strategic Necessity? Journal of Business Ethics, 99(1), 9-16. https://doi.org/10.1007/s10551-011-1161-x

Fiske, S. T., \& Taylor, S. E. (1991). Social cognition (2nd ed.). New York: McGraw-Hill.

Gilbert, D. T., \& Malone, P. S. (1995). The correspondence bias. Psychological Bulletin, 117(1), 21-38. https://doi.org/10.1037/0033-2909.117.1.21

Hair, J. F., Matthews, L. M., Matthews, R. M., \& Sarstedt, M. (2017). PLS-SEM or CB-SEM: updated guidelines on which method to use. Int. J. Multivariate Data Analysis, 107-123. https://doi.org/10.1504/IJMDA.2017.10008574

Hofman, P. S., \& Newman, A. (2013, May 28). The impact of perceived corporate social responsibility on organizational commitment and the moderating role of collectivism and 
masculinity: evidence from China. The International Journal of Human Resource Management. https://doi.org/10.1080/09585192.2013.792861

Hofstede, G. (1984). Culture's consequences: International differences in work-related values. SAGE PUBLICATIONS.

Hofstede, G. (1985). The Interaction Between National and Organizational Value System. Journal of Management Studies, 22(4), 347-357. https://doi.org/10.1111/j.1467-6486. 1985.tb00001.x

Hunt, S. D., \& Vitell, S. (1986). A general theory of marketing ethics. Journal of Macromarketing, 8(I), 5-16. https://doi.org/10.1177/027614678600600103

Hur, W. M., \& Kim, Y. (2007). How Does Culture Improve Consumer Engagement in CSR Initiatives? the Mediating Role of Motivational Attributes.

Izraeli, D. (1998). Ethical beliefs and behavior among managers: A cross-cultural perspective. Journal of Business Ethics, 7(4), 263-271. https://doi.org/10.1007/BF00381831

Katz, J. P., Swanson, D. L., \& Nelson, L. K. (2001). Culture-based expectations of corporate citizenship: A propositional framework and comparison of four. The International Journal of Organizational Analysis, 9(2), 149-171. https://doi.org/10.1108/eb028931

Kluckhohn, F. R., \& Strodtbeck, F. L. (1961). Variations in value orientations. Evanston, Ill., Row, Peterson.

Kuoppala, J., Lamminpa“a, A., Tomppo, I. V., Sc, L. S., \& Hinkka, K. (2011). Employee well-being and sick leave, occupational accident, and disability pension a cohort study of civil servants. Journal of Occupational and Environmental Medicine, 53(6), 633-640. https://doi.org/10.1097/JOM.0b013e31821aa48c

Maignan, I., \& Ferrell, O. C. (2000, Feb). Measuring Corporate Citizenship in Two Countries: The Case of the United States and France. Journal of Business Ethics, 23(3), 283-297. https://doi.org/10.1023/A:1006262325211

Moskowitz, G. B. (2005). Social Cognition : Understanding self and others. New York: Guilford Press.

Paolillo, J. G. P. (2003). The perceived role of ethics and social responsibility: A study of marketing professionals. Business Ethics Quarterly, 13(1), 63-86. https://doi.org/ 10.5840/beq20031315

Peobody, D. (1985). National Characteristics (European Monographs in Social Psychology). Cambridge, UK: Cambridge University Press.

Puohiniemi, M. (1995). Values, Consumer Attitudes and Behaviour: An Application of Schwartz's Value Theory to the Analysis of Consumer Behaviour and Attitudes in Two National Samples. University of Helsinki.

Sarfraz, M., Qun, W., Abdullah, M. I., \& Alvi, A. T. (2018, july 12). Employees' Perception of Corporate Social Responsibility Impact on Employee Outcomes: Mediating Role of Organizational Justice for Small and Medium Enterprises (SMEs). Sustainability, 10(2429). https://doi.org/10.3390/su10072429

Scholtens, B., \& Dam, L. (2007). Cultural Values and International Differences. Journal of Business Ethics, 75, 273-284. https://doi.org/10.1007/s10551-006-9252-9 
Sonnentag, S. (2003). Recovery, Work Engagement, and Proactive Behavior:A New Look at the Interface Between Nonwork and Work. Journal of Applied Psychology, 88(3), 518-528. https://doi.org/10.1037/0021-9010.88.3.518

Stawisk, S., Deal, J. J., \& Gentry, W. (2010, June). Employee Perceptions of Corporate Social Responsibility.

Story, J., \& Neves, P. (2014). When corporate social responsibility (CSR) increases performance: exploring the role of intrinsic and extrinsic CSR attribution. Business Ethics: A European Review. https://doi.org/10.1111/beer.12084

Thomas, J. (2003). The perceived role of ethics and social responsibility. Business Ethics Quarterly, 13(1), 63-86. https://doi.org/10.5840/beq20031315

Triandis, H. C. (1989). The Self and Social Behavior in Differing Cultural Contexts. Psychological Review, 96(3), 506-520. https://doi.org/10.1037/0033-295X.96.3.506

Vitell, S. J., Nwachukwu, S. L., \& Barnes, J. H. (1993, Oct). The Effect of culture on Ethical Decision-Making: An Application of Hofstede's Typology. Journal of Business Ethics, 12(10), 753-760. https://doi.org/10.1007/BF00881307

Vitell, S. J., Paolillo, J. G., \& Thomas, J. L. (2003). The Perceived Role of Ethics and Social Responsibility: A Study of Marketing Professionals. Business Ethics Quarterly, 13(1), 63-86. https://doi.org/10.5840/beq20031315

Vlachos, P. A., Panagopoulos , N. A., \& Rapp, A. A. (2013). Feeling Good by Doing Good: Employee CSR-Induced Attributions, Job Satisfaction, and the Role of Charismatic. Journal of Business Ethics, 118(3), 577-588. https://doi.org/10.1007/s10551-012-1590-1

Vlachos, P. A., Theotokis, A., \& Panagopoulos, N. G. (2010). Sales force reactions to corporate social responsibility: Attributions, outcomes, and the mediating role of organizational trust. Industrial Marketing Management, 39(7), 1207-1218. https://doi.org/10.1016/j.indmarman.2010.02.004

Walumbwa, F. O., Wang, P., Wang , H., Schaubroeck, J., \& Avolio, B. J. (2010). Psychological processes linking authentic leadership to follower behaviors. The Leadership Quarterly, 21(5), 901-914. https://doi.org/10.1016/j.leaqua.2010.07.015

Werther, W. B., \& Chandler, D. (2011). Strategic Corporate Social Responsibility: Stakeholders in a Global Environment. Los Angeles: SAGE Publications.

Williams, G., \& Zinkin, J. (2008, April). The effect of culture on consumers' wilingness to punish irresponsible corporate behaviour: applying Hofstede's typology to the punishment aspect of corporate social responsibility. Business Ethics: A European Review, 17(2), 210-226. https://doi.org/10.1111/j.1467-8608.2008.00532.x

Wood, J. A., Longenecker, J. G., McKinney, J. A., \& Moore, C. W. (1988). Ethical Attitudes of Students and Business Professionals: A Study of Moral Reasoning. Journal of Business Ethics, 7(4), 249-257. https://doi.org/10.1007/BF00381828

Zhu, Q., Hang, Y., Liu, J., \& Kee-, L. H. (2012). How is Employee Perception of Organizational Efforts in Corporate Social Responsibility related to Their Satisfaction and Loyalty towards Developing Harmonious Society in Chinese Enterprises? https://doi.org/10. 1002/csr.1302 


\section{Copyright Disclaimer}

Copyright for this article is retained by the author(s), with first publication rights granted to the journal.

This is an open-access article distributed under the terms and conditions of the Creative Commons Attribution license (http://creativecommons.org/licenses/by/3.0/). 